\title{
Global material requirements for the energy transition. An exergy flow analysis of decarbonization pathways.
}

\author{
Alicia Valero ${ }^{1}$, Antonio Valero ${ }^{1}$, Guiomar Calvo ${ }^{1}$, Abel Ortego ${ }^{1}$, Sonia Ascaso ${ }^{1}$, Jose- \\ Luis Palacios ${ }^{2}$ \\ ${ }^{1}$ Research Centre for Energy Resources and Consumption (CIRCE) - Universidad de \\ Zaragoza, CIRCE Building - Campus Río Ebro, Mariano Esquillor Gómez, 15, 50018 \\ Zaragoza, Spain. \\ ${ }^{2}$ Departamento de Ingeniería Mecánica, Escuela Politécnica Nacional, Ladrón de \\ Guevera E11-253, Quito 170517, Ecuador.
}

\begin{abstract}
Moving towards a low-carbon economy will imply a considerable increase in the deployment of green technologies, which will in turn increase the demand of certain raw materials. In this paper, the material requirements for 2050 scenarios are assessed in terms of exergy to analyze the impact in natural resources in each scenario and identify which technologies are going to demand more resources. Renewable energy technologies are more mineral intensive than current energy sources. Using the International Energy Agency scenarios, from 2025 to 2050, total raw material demand is going to increase by $30 \%$, being the transport sector the one that experiences the highest increase. Aluminum, iron, copper and potassium are those elements that present a higher share of the material needs for green technologies. Besides, there are five elements that experience at least a six-fold increase in demand in that period: cobalt, lithium, magnesium, titanium and zinc. Comparing those results with Greenpeace's AE[R] scenario, which considers a $100 \%$ renewable supply by 2050 , this increase is even higher. Therefore, avoiding the dependency on fossil fuels will imply to accept the dependency on raw materials.
\end{abstract}

Keywords: energy transition, energy scenarios, mineral requirements, green technologies, exergy, IEA

\section{Introduction}

The Paris agreement's central aim is to strengthen the global response to climate change, and in the $21^{\text {st }}$ Conference of the Parties (COP21), it was agreed to hold the increase in global mean temperature from global warming to well below $2^{\circ} \mathrm{C}$ above preindustrial levels. Even more, it also has the ambitious goal to pursue efforts to limit the temperature increase even further to $1.5^{\circ} \mathrm{C}$ [1]. Still, global temperature reached in 2015 $1^{\circ} \mathrm{C}$ above pre-industrial levels [2]. To stay below $2^{\circ} \mathrm{C}$, global greenhouse gases (GHG) emissions must be cut to at least $80 \%$ below 1990 levels [3], and to accomplish this goal, all sectors must contribute.

The need to mitigate emissions is now receiving significant attention and all the sectors, public energy stakeholders, non-governmental organizations (NGO's), private sector and regional and local entities are involved in this process. Yet this transition cannot happen suddenly and roadmaps need to be established to achieve stepwise a decarbonized system [4,5]. For instance, some recommendations and studies have already been made for decarbonizing Europe [6,7], Canada [8] or and China $[9,10]$. 
Different measures have been proposed to reach this emission reduction target, the most important by the International Energy Agency [11,12], being energy efficiency measures and penetration of renewable energy sources the dominant ones. Another very used system in future predictions and scenarios to reduce emissions is to implement carbon capture storage (CCS) $[13,14]$.

Long-run energy projections are available from many organizations, with one or multiple scenarios covering a certain period of them, the farthest reaching 2060. Those scenarios are generated according to future consumption trends, economic and population growth, share of renewable energy sources implemented each year, environmental and energy policies, etc. Some of the most relevant at international level are the following:

- International Energy Agency (IEA). World Energy Outlook, updated each year, incorporates projections for both demand and supply for renewable and nonrenewable energy sources [11].

- Another relevant report regarding future scenarios is the Energy Technology Perspectives [12], also published by the IEA. Energy technology perspectives, published yearly, outlines the trends and technological advances that will reshape the global energy sector.

- U.S. Energy Information Administration (EIA). The International Energy Outlook, updated yearly, provides an assessment of international energy markets through 2040 [15].

- MIT Joint Program on the Science and policy of global change. In the last report, Food, Water, Energy, Climate Outlook, perspectives from 2016, along with GHG emissions, issues concerning global agricultural and water resource challenges are also addressed [16].

- British Petroleum (BP) yearly makes available an Energy Outlook report outlining the most probable path for global energy markets in the next 20 years [17].

- Greenpeace first published the Energy [R]evolution Scenario in 2005, being the fifth and latest edition the one published in 2015 [18].

- World Wildlife Fund (WWF), explored in The Energy Report [19] how to power the world using only renewable energy by 2050 , generating a very ambitious scenario.

- World Energy Council provides three different projections up to 2060, considering energy security, energy equity and environmental sustainability [20]

- ExxonMobil analyzes the global energy demand and supply through 2040 not only for their long-term investments but also for the public to help promote the understanding of the world's energy needs [21].

- The Institute of Energy Economics Japan (IEEEJ) made public the Asia/World Energy Outlook 2016 in October with two different scenarios, the reference scenario, without reflecting low-carbon measures, and an Advanced Technologies Scenario (ATS) where low-carbon technologies are promoted [22].

It is noteworthy that, in all these scenarios and projections, only the energy sector is considered. Yet there are other issues to be addressed, being one of them the materials that are going to be needed to build the green technologies required to reach the $2^{\circ} \mathrm{C}$ target used as a common reference.

Some authors have analyzed metal requirements of low-carbon power generation using a Life Cycle Assessment approach for selected technologies [23,24]. On the other 
hand, there are also other prominent studies that focus only on the so-called critical raw materials that are necessary for green technologies [25,26] and for decarbonizing the energy sector in Europe [27]. From these studies, it can be seen that renewable energy technologies are more mineral intensive than current energy sources. Still, there is a lack of integration of this information with the future energy scenarios. One of the first attempts to include material requirements in energy modeling was made in [28], but they only considered a few metals.

For this endeavor, this paper analyzes several scenarios for this energy transition incorporating not only information regarding the decrease of fossil fuel energy sources and increase of renewable energy sources, but also the mineral requirements for each sector.

In order to do this, our unit of measure will be exergy, as it is the only way to assess the physical quality of resources and avoid the problems of adding "apples with oranges". The main goal is then to quantify the evolution of natural resources demand up to 2050 in terms of exergy, analyze the impact in natural resources in each scenario and identify which technologies are going to demand more resources. With this approach, we expect to be able to answer the following questions: Will there be a net exergy reduction of non-renewable resources consumption? What is the relative importance that mineral resources are going to have in the transition? Is this energy transition going to be really renewable?

\section{Methodology}

First, to be able to analyze material requirements, a selection of scenarios is necessary for current and future situations, as this will influence the amount of minerals needed in the different sectors. It must be taken into account that a scenario is a description of a possible future state of the world, one alternative image of how the energy and materials are going to be in the future, but this could rapidly change according to changes in political, social and environmental conditions.

Once the scenarios are selected, the material requirements of each green technology can be analyzed. Then, combining both results with an exergy approach, the weight that mineral resources are going to have in the transition can be assessed.

\subsection{Scenarios}

For the analysis of mineral requirements, two different reports, each one with several scenarios, have been taken into account.

First, we have considered the most relevant and recognized scenarios at world level, those published by the International Energy Agency. In this case, the 2017 Energy Technology Perspectives report will be used as a source of information regarding the energy demand, the energy use by sector and the global installed capacity [12]. This report analyzes three different scenarios:

- Reference technology scenario (RTS) that takes into account current commitments to limit emissions and improve energy efficiency. It already presents meaningful variances with the "business as usual" approach. These efforts will result in a temperature increase of $2.7^{\circ} \mathrm{C}$ by 2100 .

- $2^{\circ}$ Scenario (2DS), that takes into account a $70 \%$ reduction of $\mathrm{CO}_{2}$ emissions in the energy sector from today's levels by 2060 . It is a highly ambitious scenario 
where there is a $50 \%$ change of limiting the temperature increase by 2100 to only $2^{\circ} \mathrm{C}$.

- Beyond $2^{\circ} \mathrm{C}$ scenario (B2DS), being the most optimistic scenario, technology improvements and policies are pushed to the maximum in order to achieve netzero emissions by 2060 , still, it does not define a specific temperature increase by 2100 , only that it will be below $2^{\circ} \mathrm{C}$.

Greenpeace, in its Energy Revolution report, presents one of the most ambitious renewable energy scenarios [18]. They also describe three scenarios:

- Reference scenario (RS), reflecting a continuation of current policies and trends taking into account information of the IEA.

- Energy [R]evolution scenario (E[R]), follows worldwide key target to reduce carbon dioxide emissions in order to hold the increase in global temperature under $2^{\circ} \mathrm{C}$. A second objective is the global phasing out of nuclear energy.

- Advanced Energy [R]evolution scenario (AE[R]), the most ambitious one, with significant efforts compared to the previous scenario to achieve a $100 \%$ renewable energy supply in 2050. The consumption paths are the same as in $\mathrm{E}[\mathrm{R}]$ but there is a much faster introduction of new technologies.

For the study, the 2DS scenario of the IEA will be used as the main source of information as it is arguably the most cited worldwide. IEA's B2DS scenario, Greenpeace's AE[R] scenario and World Energy Council (WEC) scenarios, are going to be considered later for comparative purposes.

\subsection{Material use in the energy sector}

When analyzing the energy sector, material needs must be considered, as more often than not they are not taken into account when analyzing the shift towards a low-carbon economy. Green technologies are specially demanding regarding material needs and scarce elements thus they could even generate bottlenecks or supply problems in the future, and this is a key aspect that should be analyzed.

In this paper, the green technologies that are included in the analysis are the following: wind power, solar photovoltaic (PV), concentrated solar power (CSP), solar thermal, geothermal, hydropower and the mobility sector, with special emphasis on Electric Vehicles (EV) composed by the addition of Plug Hybrid Electric Vehicles (PHEV) and Battery Electric Vehicles (BEV).

Tables in Appendix A (Tables A.1. and A.2) show the material intensity in each one of the technologies and vehicles considered, it is assumed that the composition and proportion of each element will not change from now until 2050. For non-renewable energies, materials needed to build nuclear and gas facilities are also considered (Table A.3), mainly focused on the amount of steel used, as usually steel has significant proportions of chromium and manganese. It is also assumed that no new power plants facilities that use coal or oil will be built, thus they will not generate any new material demand in the following decades. All data have been obtained from [29].

As the material intensity of each technology is known, the next step is to calculate the amount of materials used each year are the energy projections, retrieved from the selected scenarios, and the sales projections by type of vehicle [30,31].

To calculate the raw material demand in each green technology it has been considered that a certain amount of raw materials comes from recycling processes [32]. 
Equation 1 shows how material demand in the studied green technologies is calculated for a given year for each commodity:

$$
d_{a_{-} g t}=\left[\sum_{i=1}^{i=m} N * M *(1-r)\right]
$$

where $d_{a_{-g t}}$ is the quantity of primary material $a$ demanded for the analyzed green technologies (gt) during a given year; $N$ is the number of yearly manufactured units of each technology; $M$ is the quantity of material $a$ demanded by each technology to manufacture one functional unit - FU (for renewables, FU=1MW; for passenger cars $\mathrm{FU}=1$ vehicle); $r$ is the share of material which comes from recycling and $i$ is each studied technology.

Besides, material demand from renovation and repowering activities in renewable energies and passenger vehicle fleet must also be considered, following Equation 2:

$$
N=N_{n s}+N_{r n}
$$

where $\mathrm{N}_{\mathrm{ns}}$ is the number of new units which are added to the global market and $\mathrm{N}_{\mathrm{rn}}$ is the number of units manufactured to renew old installations.

Additionally, as the production of phosphorous and potassium is very important in the food sector, (95\% and $92 \%$ is used for fertilizers, respectively, [33,34], a special analysis has been made. For the use in the food sector, estimations made by Alexandratos and Bruinsma [35] state that from 2005 to 2030 the annual growth of fertilizer consumption is expected to be $1.4 \%$ and from 2030 to $2050,0.7 \%$. This is in line with other estimations made by Blanco [36] and FAO [37].

Besides, the bioenergy sector will also demand a certain amount of $\mathrm{P}$ and $\mathrm{K}$ in the coming decades; therefore a complementary analysis was carried out (Table 1). This demand has been calculated taking into account the bioethanol and biodiesel supply rate at worldwide level and the IEA projections $[38,39]$.

Table 1. Bioenergy expected mineral demand (data in million tonnes).

\begin{tabular}{lccccccc}
\hline & $\mathbf{2 0 2 0}$ & $\mathbf{2 0 2 5}$ & $\mathbf{2 0 3 0}$ & $\mathbf{2 0 3 5}$ & $\mathbf{2 0 4 0}$ & $\mathbf{2 0 4 5}$ & $\mathbf{2 0 5 0}$ \\
\hline $\mathbf{P}$ & 7 & 8.5 & 10 & 11.2 & 13 & 14.2 & 17 \\
\hline $\mathbf{K}$ & 13 & 15 & 17 & 20 & 22 & 27 & 30 \\
\hline
\end{tabular}

Hence, total future estimations of $\mathrm{P}$ and $\mathrm{K}$ take into account both uses, for fertilizers (used in the agriculture sector) and for the bioenergy sector.

\subsection{Material use in the non-energy sector}

The main goal is to analyze the material use in the energy sector but the demand in other sectors must also be considered to have a more robust and complete analysis of the energy transition. It should be stated that only 35 elements are being analyzed in this paper, which in 2016 represented around $76 \%$ of the total world mineral production. Therefore the different hypotheses presented in this section only consider production and demand of these 35 elements.

Using the material demand for renewable energy systems (RES) for 2016 through material intensity data from Tables A.1 and A.2 and the world mineral production for that same year, the demand of the remaining sectors can be calculated as the difference between both. Then, as we already know the material use for the RES sector in the 
future scenarios, the only missing information is the material use in the non-RES sector. For this endeavor, three different hypotheses have been considered:

a) Material Demand - population linked (MDP): as the increase in population is expected to grow $0.8 \%$ annually, this same rate will be the one used to calculate the material demand for non-RES sector. This is the most conservative hypothesis.

b) Material Demand - Hubbert (MDH): using future mineral production calculated with the Hubbert peak model for each mineral analyzed [40], the total mineral production from 2018 to 2050 can be estimated as the sum of the yearly estimated production of each mineral.

c) Material Demand - business as usual (MDBAU): the evolution of the material intensity (tonnes per capita) of the 35 selected elements has been analyzed for the last 33 years, from 1983 to 2013 , going from 0.223 to 0.395 , respectively. Using this trend, future material intensity can be calculated assuming that the growth is going to be the same from 2017 to 2050 .

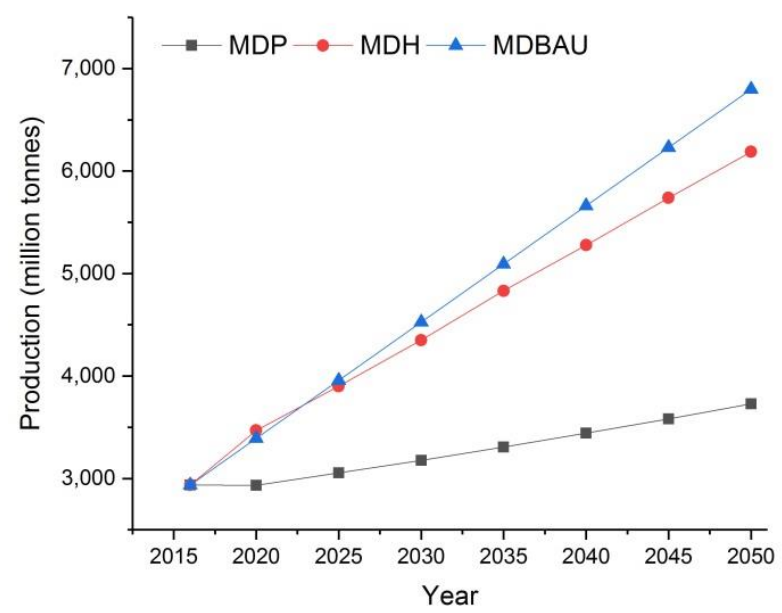

Figure 1. Material demand for non-RES sectors considering: MDP - material demand increases the same as population $(0.8 \%$ per year). $\mathrm{MDH}$ - material demand increases following Hubbert peak curves. MDBAU - Material intensity increases following the same trend than in the last 33 years.

\section{Exergy analysis}

Exergy is defined as the maximum amount of work that may be generated when bringing a thermodynamic system into equilibrium with its surrounding environment. It has been traditionally used to measure any energy source, to identify irreversible energy conversion processes, quantify thermodynamic losses and to improve the design and operation of energy systems mitigating their impacts on the natural environment. More recently, it has also been used, combined with economic and environmental considerations, for exergoeconomic and exergoenvironmental analysis [41,42]. In this paper, exergy is going to be used to assess the quality of the minerals used in renewable technologies. The advantage of doing so is that raw materials can be assessed with the same unit of measure than energy sources, i.e. in tons of oil equivalent.

Exergy of primary fossil resources can be approximated with no significant error to their HHV [43]. Usually, energy scenario reports already provide the information in energy units (i.e. PJ or Mtoe), thus considering already this fact. The exergy of electricity is equivalent to their energy content and thus, renewable energy data is 
already expressed in exergy terms. The main difference with conventional flow analysis relies then in how to assess raw materials. Usually, when raw materials flows are easily obtained and in turn it can provide useful information without having to carry out detailed data processing. That said these data is not enough if the quality of the raw materials considered wants to be taken into account. For instance, one tonne of gold cannot be compared to one tonne of iron as, even if the weight is indeed the same, the energy needed to extract those amounts and the quality of each element is considerably different. To overcome this issue, exergy analysis can help to evaluate raw materials, especially mineral resources, using objective information that goes beyond tonnage. Whilst fuel quality remains fairly constant with extraction, for the case of non-fuel minerals the quality decreases while mining continues - ore grades decline and more energy per unit of metal obtained increases [44]. Therefore, using exergy, one can physically measure the "rarity" of a piece of mater, as the rarer something is, the more it stands out [45].

Chemical exergy alone cannot reflect that fact. This is why when analyzing non-fuel minerals, exergy replacement costs (ERC) are preferred [46,47]. These represent the natural free bonus provided by nature for having the minerals concentrated in mines instead of dispersed in the crust. They are equivalent to the exergy that would be needed to extract a mineral from ordinary rock using prevailing technology to the concentration and composition found in the mine [48]. To be able to do these calculations, average values of ore grade in mines and in the crust are needed for each element. The values and the calculation methodology are fully explained in [49] and [48]. Nevertheless, these values are not static over time as they are technology dependent. Still, if there are no significant technology improvements in the short term ERC values will remain within the same range [50]. ERC values are expressed in GJ/ton and the higher the value, such as the case of PGM, Ta and In, the scarcer ant the more energy intensive to obtain the element (Table B.1). It should be mentioned that the exergy represented in the material flows is not a real energy expenditure. The real energy expenditure used for mining and obtaining the different mineral commodities is already included in the corresponding primary energy flows. Rather, it should be considered as a proxy measured in exergy terms, of the quality of each of the minerals used.

\section{Exergy flow analysis}

First, the exergy flow analysis has been carried out for the International Energy Agency $2^{\circ}$ Scenario (2DS), which limits the temperature increase by 2100 to only $2^{\circ} \mathrm{C}$. We have used 2025 and 2050 data, as already in 2025 some changes in the energy sector are visible and 2050 since it is the common point that all energy scenario reports have. Subsequently, results of IEA scenarios are compared with other scenarios (especially with Greenpeace's $\mathrm{AE}[\mathrm{R}]$ ) to state the differences in raw material consumption for each case. These two sections are carried out assuming that the demand in non-RES sectors will only grow following the population growth $(0.8 \%$ per year). For this reason it is important to take into account other situations, such as those mentioned before, the MDH and MDBAU scenarios, considering that material demand grows according to the Hubbert peak model and that the increasing trend is the same than in the last 33 years, respectively.

\subsection{International Energy Agency 2DS scenario}


The 2DS scenario tackles the necessary route to limit the increase in global temperature below $2^{\circ} \mathrm{C}$ with a $50 \%$ chance. In this scenario, $\mathrm{CO}_{2}$ emissions will peak before 2020 and fall to around one-quarter of today levels by 2060, continuing its decline to reach neutrality in the energy system by 2100 . Efficiency and renewable energies will be the main contributors, with a $40 \%$ and $35 \%$ of the share, respectively. Fuel switching will contribute 5\% and nuclear 6\%. Furthermore, other technologies still in development will be needed; the most important being Carbon Capture and Storage (CCS), accounting for $14 \%$ of the decrease. CCS is a complex process that can be defined as the capture of $\mathrm{CO}_{2}$ from a fossil fuel emitting power plant or other facilities, the clean-up and compression processes, the storage site and the means to transport it to a permanent location [14]. According to IEA predictions, the capture and storage development rate would need to increase tenfold in order to meet its objectives.

The 2DS scenario is obtained with the integration and manipulation of data from four sub-models or subsectors: energy conversion, industry, transport and buildings (residential and commercial/services). For instance, the power sector is expected to be decarbonized by 2060, as it is fundamental to help decarbonize the end-use sectors, for example, by using heat pumps in buildings or electric vehicles for transport.

In all sub-sectors, energy efficiency is essential. Renewable energies deployment will be faster in the power sector, and will be also important in the transport (biofuels), buildings (renewable-based heating) and industry sectors (renewable feedstock). By 2025 the $\mathrm{CO}_{2}$ emissions will decrease mainly due to the first effects of the efficiency measures applied and the take-off of renewable energies.

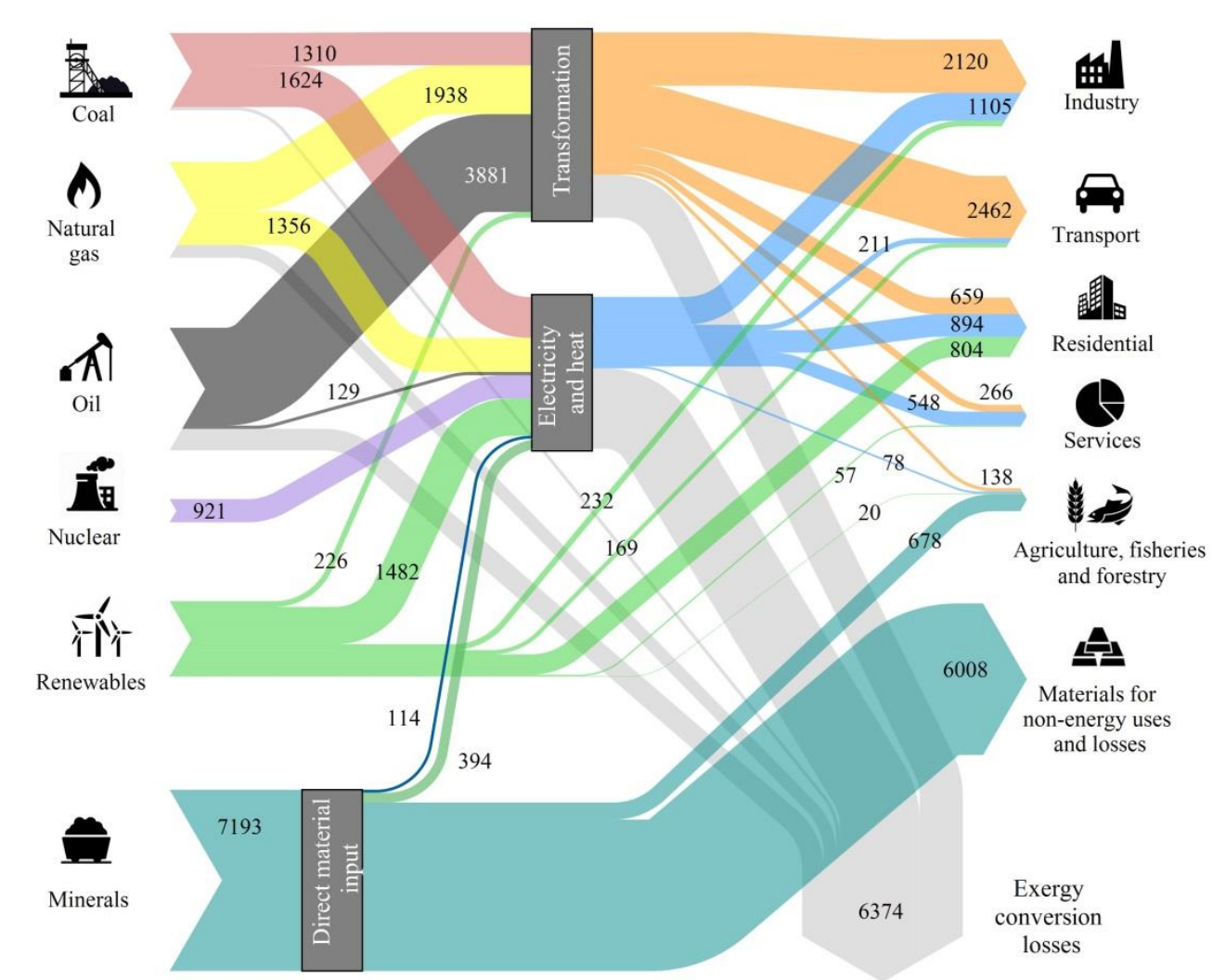

Figure 2. World exergy flow analysis for the IEA 2DS scenario for the year 2025. All data are expressed in Mtoe. 
An analysis of the world exergy flows, using Sankey diagrams, has been made for the year 2025 using IEA information (Figure 2). All the flows in the figure are expressed in Mtoe. Coal, natural gas, oil and nuclear energy are used both for transformation and for electricity and heat. Regarding renewables, they are also used for transformation and heat but a considerable amount goes directly to the sub-sectors considered: industry, transport, residential, services, agriculture, fisheries and forestry. Regarding mineral flows, a substantial part is used for non-energy uses (6,008 Mtoe) and the rest is divided between minerals for non-RES and RES energy uses, 114 and 394 Mtoe, respectively.

Comparing 2025 and 2050 for the 2DS scenario (Figures 2 and 3), there is a considerable decrease in the total primary demand of fossil fuels, 57, 31 and $27 \%$, for coal, oil and natural gas, respectively. To compensate this decrease, there is an increase in the remaining energy sources, for instance, $94 \%$ in the case of nuclear energy. Especially notable is the use of renewable sources of energy, which increases $131 \%$ in only 25 years according to the 2DS scenario.

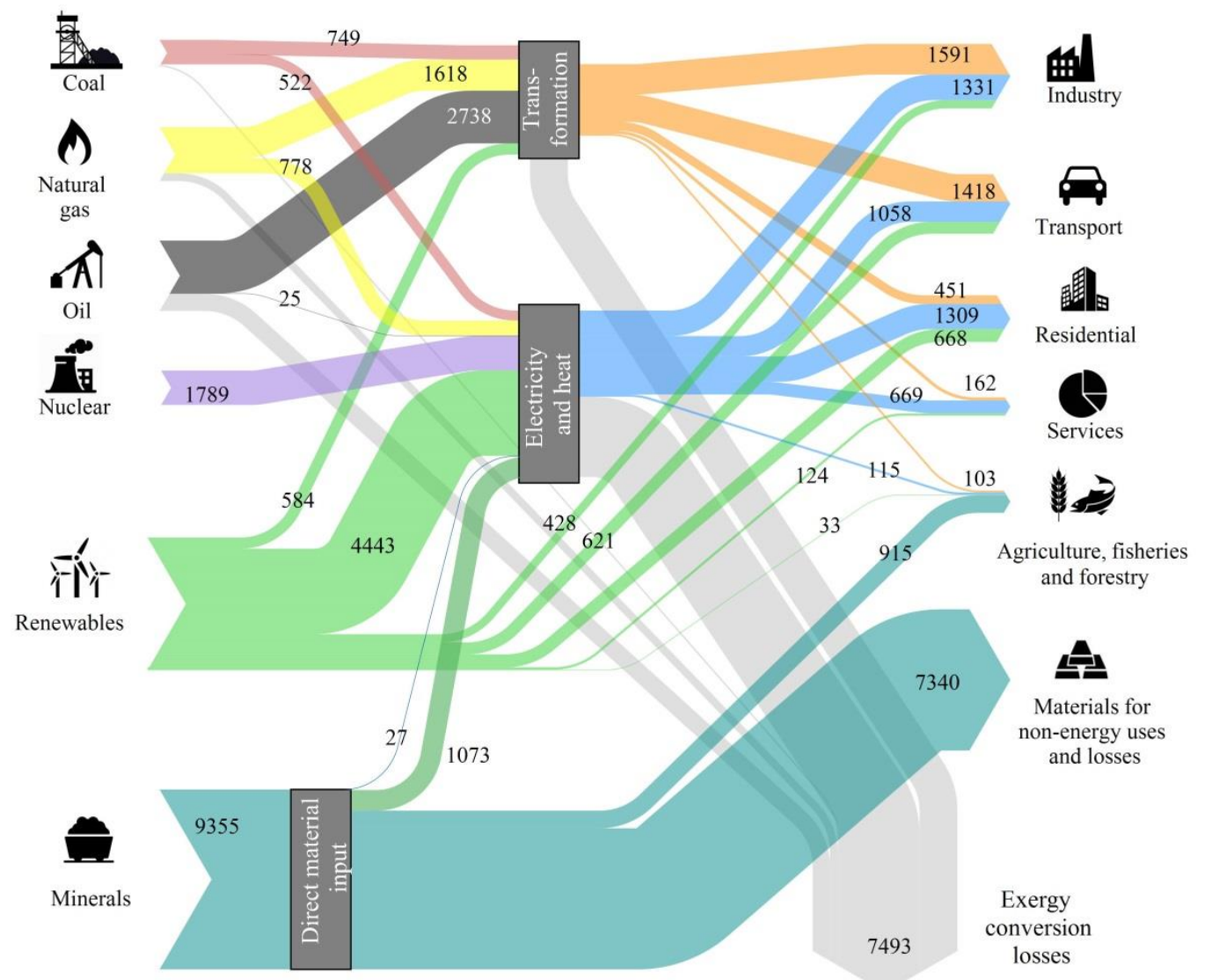

Figure 3. World exergy flow analysis for the IEA 2DS scenario for the year 2050. All data are expressed in Mtoe.

Associated to that increase in the use of renewable energies, there is also an increase in raw material demand. From 2025 to 2050, total raw material demand expressed in exergy terms increases by $30 \%$ if the IEA projections are met. If we analyze this increase, it mainly corresponds to the increase of raw materials needed in the energy sector. Taking into account bioenergy and materials needed for RES, the increase in that period of time is $172 \%$ (from 394 to 1073 Mtoe), while the material increase in agriculture for fertilizers and non-energy uses is only 35 and $22 \%$, 
respectively. Noteworthy is the decrease of material demand for non-RES energy uses, that decreases considerably, from 114 Mtoe to only 27, and that is associated to the decrease of fossil fuel consumption.

Regarding material use by sector, transport is the sector that experiences the highest increase. Taking into account materials used in BEV and PEV only, there is a total material increase of $344 \%$ from 2025 to 2050 . The meeting of 2025 EV sales objective implies a growth of $35 \%$ every year, from 2017 to 2025; this was already accomplished in 2015 and 2016. The growth rate must continue at 30\% every year to 2050 .

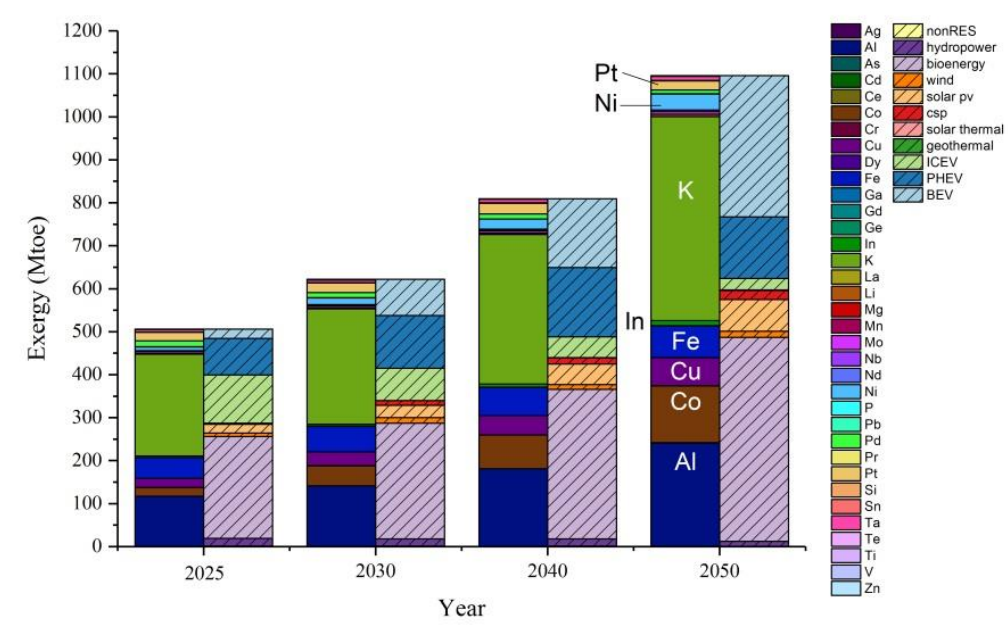

Figure 4. Raw materials exergy demand evolution for the EIA 2DS scenario from 2025 to 2050 for energy uses by element and by technology. All data are expressed in Mtoe.

Once seen the general picture of the energy transition for both years for the 2DS scenario, the raw material energy demand by element and technology can be analyzed for RES and non-RES energy uses (Figure 4). Aluminum, iron, copper and potassium represent a high share of the material needs in all analyzed years. Aluminum, copper and iron are the most used metals in all technologies, going from wind, solar to all types of vehicles. The amount of potassium and phosphorous required in this case only corresponds to the demand generated by the bioenergy sector, which is expected to double by 2050 . As it can be seen in the figure, only potassium stands out and this is due to the differences between the ERC values of each substance. Besides, there are 5 elements that experience at least a six-fold increase in demand: cobalt, lithium, magnesium, titanium and zinc. Cobalt and lithium are mainly used in BEV and PHEV, while magnesium, titanium and zinc are used in CSP and solar thermal. The sales of PHEV are expected to increase from 5 million in 2016 to almost 32 million in 2050 but more striking is the case of $\mathrm{BEV}$, whose sales are expected to increase from 0.3 to 40 million of units. In the 2DS scenario, CSP goes from $7 \mathrm{GW}$ of gross electricity capacity in 2014 to $720 \mathrm{GW}$ in 2050, which is the type of energy that experience the highest increase only after ocean energy (from 0.5 to $153 \mathrm{GW}$ in that same period). Therefore it seems logical than material demand associated with both extreme growths increases considerably.

On the other hand, the demand of some minerals will decrease in the energy sector. This is the case of chromium, lead and palladium. In the case of chromium, even if it is used in renewable sources of energy, it is also used in large quantities for ICEV. A similar situation can be observed for lead and palladium, mainly used in ICEV and PHEV. As the ICEV sales are expected to decrease around 82\% from 2016 to 2050, the decrease in demand is clearly associated to the decrease in sales. This does not mean 
that the demand of those elements will decrease in general terms, as they are used in other sectors or could be used in applications even not known today.

\subsection{Other scenarios}

Until now, only the 2DS scenario has been analyzed, taking into account materials demanded by green technologies from 2025 to 2050 and considering an increase of $0.8 \%$ per year in the material demand of the remaining sectors.

In addition to the 2DS scenario, the IEA also included the B2DS scenario [12], where the temperature increase by 2100 is less than $2^{\circ} \mathrm{C}$. In order to accomplish the restrictions needed in the B2DS scenario, the decarbonisation of the energy sector is drastically accelerated and the emission reduction in end-use sector becomes significantly more challenging. CCS is one of the largest contributions to emissions reductions in the shift from the 2DS to B2DS at 32\%. Energy efficiency contributes $34 \%$, while fuel switching (18\%), renewables $(15 \%)$ and nuclear $(1 \%)$ provide the remainder of the emissions reductions. In the power sector an even more accelerated deployment of low carbon technologies and transition to negative emission using BECCS after 2040 is assumed. In buildings a rapid shift to high-performance lighting and appliances in the next years in needed. In the transport sector decarbonisation is faster than in 2DS. All this requires broad adoption of the most advances technologies and very stringer policies.

In the $\mathrm{AE}[\mathrm{R}]$ scenario, Greenpeace [18] makes the necessary assumptions to transform the energy system towards a $100 \%$ renewable energy supply. In this scenario global $\mathrm{CO}_{2}$ emissions stabilize by 2020 and then a constant reduction leads to zero emissions in 2050 , being thus the temperature increase less than $2^{\circ} \mathrm{C}$. Efficiency improvements and the best available technologies in all sectors are key. A fast introduction of new technologies leads to a complete decarbonisation of the power, heat and transport sectors. In contrast to the B2DS scenario, CCS technologies are not implemented, and nuclear power disappears quickly. Current lignite and coal power plants lifetime is reduced. Biomass power generators and large hydro power remain limited. Wind power and solar power (both photovoltaics and concentrating solar power) are considered the main pillars of power supply, complemented with geothermal, ocean energy and small and medium sized hydropower. Besides direct use of renewable electricity and biofuels, the transport sector is complemented by hydrogen generated by electrolysis using renewable energy, which is converted to synthetic hydrocarbons to replace fossil fuels in heavy duty vehicles and air transportation. Hydrogen is also used in industry, heating and power sectors to help in the replacement of natural gas, replacing 30-40\% of the remaining gas consumption in 2040 and $100 \%$ in 2050 .

The WEC scenarios [20] are not constrained by a $\mathrm{CO}_{2}$ budget but by different predominantly driving forces: market in Modern Jazz and governments in Unfinished Symphony. Modern Jazz represents a competitive world driven by market mechanisms and rapid technology innovation. An international climate policy is absent and the energy transition is due to rapid improvements in technology innovation. In this scenario final energy consumption to 2060 grows 38\%, primary energy demand $25 \%$ and the $1,000 \mathrm{Gt} \mathrm{CO}_{2}$ carbon budget is exceeded in the early 2040s with a cumulative carbon emission around 1,490 Gt $\mathrm{CO}_{2}$ for 2015-2060. In Unfinished Symphony, national governments are united and take effective policy action on climate change with an extensive network of fiscal incentives, such as green subsidies and carbon pricing. 
Circular and sustainable economies are in place driven by societal values and strong 476 global governance. In this scenario final energy consumption to 2060 grows 22\%, 477 primary energy demand $10 \%$ and the cumulative carbon emission are $1.165 \mathrm{Gt}^{\mathrm{CO}_{2}}$ 478 between 2015-2060. Intermittent renewable energy will account for 30\% and 39\% of power generation in Modern Jazz and Unfinished Symphony respectively.

Table 2 shows global installed capacity data for all the scenarios analyzed in this section. IEA 2DS scenario has already been analyzed in detail in previous sections. B2DS scenario and WEC scenarios, both Jazz and Unfinished symphony, provide results for 2050 within the same order of magnitude than 2DS. The most optimistic or ambitious scenario, where fossil fuels are no longer used as energy sources and where renewable energy sources experience the highest increase, is AE[R]. For this reason, the comparative analysis is going to be carried out between the 2DS scenario and the AE[R] scenario to better understand what would imply, in terms of materials demand, to reach a $100 \%$ renewable scenario. It is important to state than in Greenpeace's scenario, hydrogen plays a major role but that this technology has not been included in our material demand analysis due to lack of data.

Table 2. Global installed capacity for the different scenarios (all data in GW).

\begin{tabular}{|c|c|c|c|c|c|c|c|c|}
\hline & \multirow{2}{*}{\multicolumn{2}{|c|}{ IEA 2DS }} & \multirow{2}{*}{\multicolumn{2}{|c|}{ IEA B2DS }} & \multirow{2}{*}{\multicolumn{2}{|c|}{ GP AE[R] }} & \multirow{3}{*}{\multicolumn{2}{|c|}{\begin{tabular}{cc}
\multicolumn{2}{c}{ WEC } \\
Jazz & $\begin{array}{c}\text { Unfinished } \\
\text { Symphony }\end{array}$ \\
2050 & 2050 \\
\end{tabular}}} \\
\hline & & & & & & & & \\
\hline & 2025 & 2050 & 2025 & 2050 & 2025 & 2050 & & \\
\hline \multicolumn{9}{|l|}{ Fossil fuels } \\
\hline Coal & 1,804 & 473 & 1,739 & 396 & 1,571 & 0 & 764 & 284 \\
\hline Oil & 397 & 169 & 411 & 182 & 202 & 0 & 95 & 69 \\
\hline Diesel & - & - & - & - & 36 & 15 & - & - \\
\hline Nat. gas & 1,944 & 2,346 & 1,989 & 1,918 & 2,021 & 0 & 3,215 & 2,284 \\
\hline Nuclear & 529 & 948 & 536 & 965 & 184 & 0 & 551 & 852 \\
\hline Hydrogen & - & - & - & - & 14 & 2,220 & - & - \\
\hline \multicolumn{9}{|l|}{ Renewables } \\
\hline Hydro & 1,413 & 2,103 & 1,414 & 2,193 & 1,368 & 1,536 & 1,709 & 1,842 \\
\hline $\begin{array}{ll}\text { Wind } & \text { (on } \\
\text { and } & \text { off } \\
\text { shore) } & \end{array}$ & 1,177 & 3,280 & 1,218 & 3,474 & 1,873 & 8,040 & 2,349 & 2,779 \\
\hline Solar PV & 885 & 4,019 & 753 & 4,424 & $2,000^{(1)}$ & $9,295^{(1)}$ & $2,915^{(1)}$ & $3,560^{(1)}$ \\
\hline Solar CSP & 60 & 720 & 96 & 939 & - & - & - & - \\
\hline Biomass & 292 & 771 & 341 & 1,289 & 295 & 742 & 272 & 340 \\
\hline Geothermal & 32 & 131 & 35 & 145 & 85 & 708 & 72 & 114 \\
\hline $\begin{array}{l}\text { Solar } \\
\text { thermal } \\
\text { power } \\
\text { plants }\end{array}$ & - & - & - & - & 177 & 2,555 & - & - \\
\hline $\begin{array}{l}\text { Ocean } \\
\text { energy }\end{array}$ & 3 & 153 & 3 & 182 & 46 & 738 & - & - \\
\hline Other & 0 & 0 & 0 & 0 & - & - & 21 & 19 \\
\hline TOTAL & 8,534 & 15,113 & 8,533 & 16,107 & $\mathbf{9 , 8 7 2}$ & 25,849 & 11,963 & 12,143 \\
\hline
\end{tabular}


Material demand, by element and by technology, for the IEA 2DS scenario and the $A E[R]$ Greenpeace scenario are shown in Figure 5. It can be seen that there is a growth in material demand both for 2025 and 2050, as the Greenpeace scenario will demand more materials. Approximately the increase between both scenarios is around $8-10 \%$ in both years.

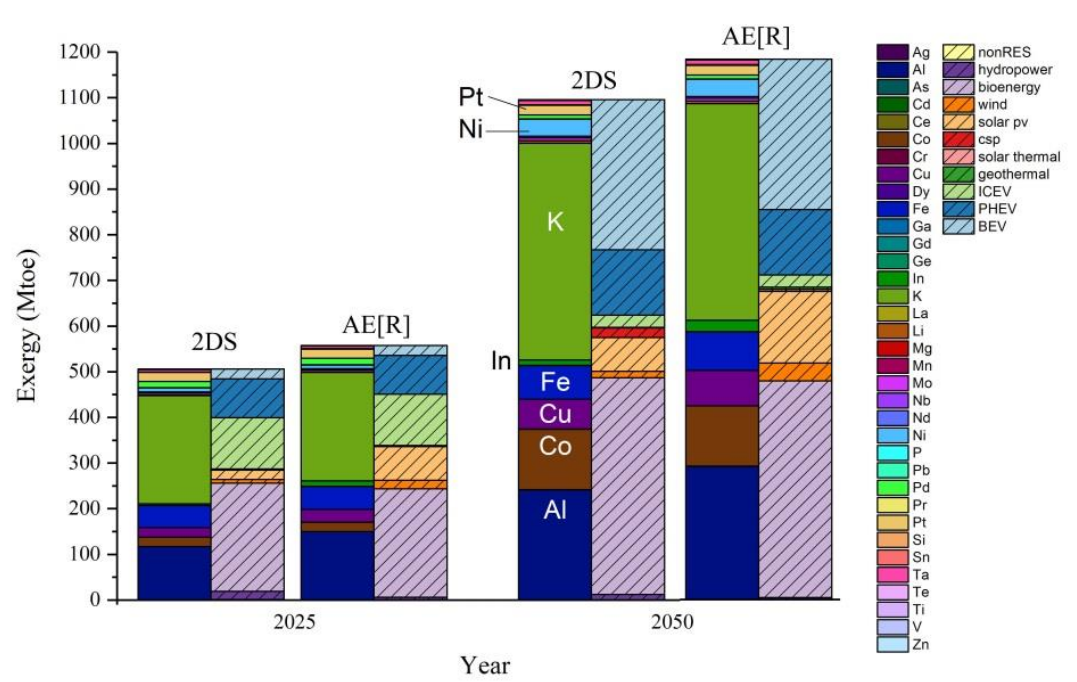

Figure 5. Raw materials exergy demand comparison between the IEA 2DS scenario and the Greenpeace advanced energy revolution (AE[R]) scenario for 2025 and 2050 by element and by technology. All data are expressed in Mtoe.

There is a severe increase in material demand, more than $200 \%$, when comparing both scenarios for 2050 in the cases of cadmium, germanium, indium, tin, tellurium and titanium. Gallium and neodymium demand for instance, increases approximately by $60 \%$ and $37 \%$ respectively, but for other elements such as aluminum, copper, dysprosium, iron, this demand only increases between 10 and $20 \%$. Besides, there is also a decrease in material demand for some other elements, such as magnesium, manganese, silver and zinc.

Regarding technologies, the most remarkable growth in material use is observed in geothermal, solar PV and wind, which is consistent as, for instance, solar PV demands almost all of the elements that experience highest increases (cadmium, germanium, indium, tin, tellurium).

\subsection{Changes in the demand of raw materials in other sectors}

Until now we have considered that the material demand in the non-RES sectors grows at the same rate than population, meaning $0.8 \%$ per year (MDP). This is a very conservative hypothesis as in the last century it has been observed that the extraction of minerals is following an almost exponential-level increase [51]. Therefore, as explained in the methodology section, two other hypotheses were used, being the first one based on the Hubbert peak model (MDH) and the second assuming that the trend in the last 33 years (from 1983 to 2016) is going to be the same than in the next 33 years (from 2017 
to 2050) (MDP). As these two last hypotheses provided similar results, the most extreme one (MDBAU) has been used for comparative purposes (Figure 6).

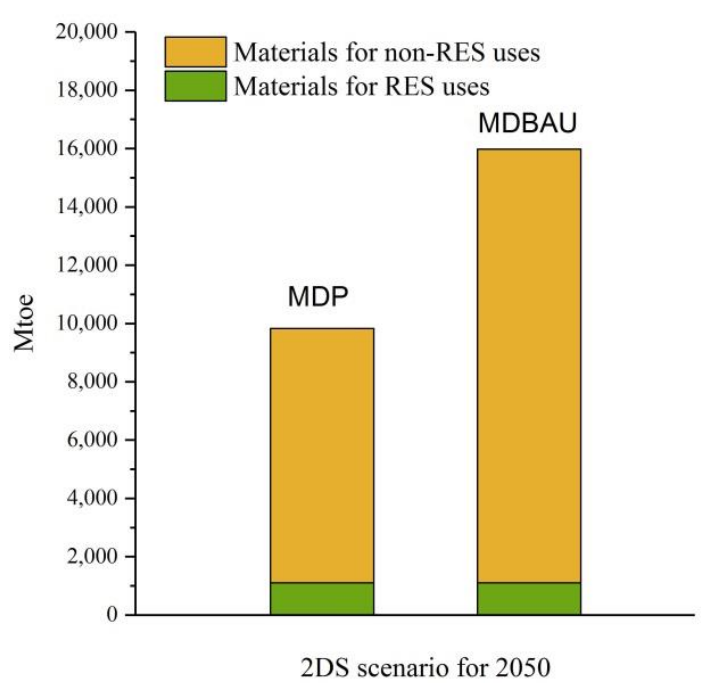

Figure 6. Total material demand for the 2DS scenario for 2050 considering two different scenarios for non-RES uses material demand (MDP and MDBAU).

When considering these two scenarios, material demand for RES uses obviously remains constant but the demand for non-RES uses changes drastically, increasing $63 \%$ between the MDP and MDBAU scenarios. As stated before, in this paper only 35 raw materials are being considered (see Table B.1 for the complete list), therefore this increase only corresponds to those commodities.

If we take into account current reserves and resources data from the USGS [52] they can be compared with the accumulated production from 1900 to 2015 plus the production estimated with the most pessimistic hypothesis from 2016 to 2050. If the ratio reserve to total accumulated production is calculated, only a few commodities seem to be able to meet that demand: aluminum, potash, lithium, niobium, phosphate rock, titanium and vanadium. If the ratio used is resources to accumulated production, then some more minerals are added to that list: arsenic, cadmium, cobalt, chromium, copper, iron, magnesite, molybdenum, lead tin and zinc.

The R/P ratio has been used in many other studies to evaluate future resource availability to assess the number of years of which the level of production of a certain year can be sustained by the available reserves or resources [53-56]. Still, reserves and resources information is not always available for all the minerals or the data is not accurate enough due to limited geological exploration. Nonetheless, even if the MDBAU scenario is the most pessimistic one, the results obtained can help to put focus on selected substances to implement specific resource management measures.

\section{Conclusions}

At the beginning of the paper we proposed three questions to which we can provide some answers, after analyzing different scenarios of the energy transition towards a low-carbon economy.

The primary demand of renewable sources of energy will increase by $131 \%$ from 2025 to 2050 according to the 2DS scenario while for coal, oil and natural gas it will decrease 57, 31 and $27 \%$, respectively. Therefore, it seems that the transition towards a low carbon economy will reduce the exergy consumption of non-renewable resources, 
at least of fossil fuels. Yet, non-fuel minerals have to be considered as well. For this reason the raw materials used to manufacture green technologies must be taken into account. The analysis shows that the mineral demand will notably increase and with it the associated exergy replacement costs.

According to the data presented by the IEA in the 2DS scenario, there is going to be a 30\% increase of mineral demand, from 7,193 Mtoe in 2025 to 9,355 Mtoe in 2050. If other scenarios where more green technologies are implemented (such as Greenpeace's $\mathrm{AE}[\mathrm{R}])$ or if different estimations of demand are considered, this increase would be even higher.

Of the 35 minerals analyzed in this study, that in 2016 represented $76 \%$ of the total extraction in weight, there are 5 elements that experience at least a six-fold increase in demand in exergy replacement cost terms: cobalt, lithium, magnesium, titanium and zinc. As stated before, cobalt and lithium are mainly used in BEV and PHEV, while magnesium, titanium and zinc are used in CSP and solar thermal, and all these technologies are expected to experience an extreme growth in that period of time. It is also important to consider the growth in $\mathrm{P}$ and $\mathrm{K}$ demand, both for non-RES (fertilizers) and RES (bioenergy) uses, as for the latter it is expected to double by 2050 . In the case of fertilizer demand in the agriculture for food sector, the increase is also considerable. Still, when analyzing the ratio of resources to accumulated production (from 1900 to 2050) of those substances, it seems that the demand could be covered.

This increase in demand will accordingly increase the pressure in the mining sector and considerably affect the energy consumption, as while new mines could still be opened in the future, current mines are seeing how the ore grade is decreasing, which in turn triggers higher energy consumption. This is because the energy consumption in a mine increases following an exponential trend when the ore grade decreases.

As it can be deduced, there is going to be a shift from fossil fuels to mineral resources consumption because "green technologies" have a greater demand in minerals than conventional technologies (i.e. conventional power plants or internal combustion vehicles vs. renewable or hybrid and electric vehicles).

Avoiding the dependency on fossil fuels will imply to accept the dependency on raw materials, some of which with important supply risks. Minerals have to be extracted from the mines or recycled, processes that require huge amounts of energy. If green technologies want to be really sustainable, more efforts in dematerialization, substitution of critical minerals and recycling must be done. Future research work will be focused on the recyclability of renewable energy technologies to find alternatives for improving eco-design and thus reduce raw material dependency.

\section{Acknowledgments}

This work was supported by the Spanish Ministry of Economy, Industry and Competitiveness (ENE2017-85224-R).

\section{References}

[1] United Nations/Framework Convention on Climate Change. Paris Agreement. 21st Conf Parties 2015:3. doi:FCCC/CP/2015/L.9.

[2] World Meteorological Organization. WMO Statement on the status of the global climate in 2015. 2016. 
[3] European Climate Foundation. Power Perspectives 2030. On the road to a decarbonised power sector. Available at: http://www.roadmap2050.eu/attachments/files/PowerPerspectives2030_FullRepo rt.pdf. 2011.

[4] Goldemberg J, Tadeo Prado L. The "decarbonization" of the world's energy matrix. Energy Policy 2010;38:3274-6. doi:10.1016/j.enpol.2010.03.040.

[5] Rosenbloom D. Pathways: An emerging concept for the theory and governance of low-carbon transitions. Glob Environ Chang 2017;43:37-50.

[6] Pleßmann G, Blechinger P. How to meet EU GHG emission reduction targets? A model based decarbonization pathway for Europe's electricity supply system until 2050. Energy Strateg Rev 2017;15:19-32. doi:10.1016/J.ESR.2016.11.003.

[7] Drummond P, Pye S, McGlade C, Mathieu C, Jurić Ž, Matosović M, et al. Chapter 10 - Decarbonizing the $\{$ EU $\}$ Energy System. In: Welsch M, Pye S, Keles D, Faure-Schuyer A, Dobbins A, Shivakumar A, et al., editors. Eur. Energy Transit. - Insights Policy Mak., Academic Press; 2017, p. 55-65. doi:https://doi.org/10.1016/B978-0-12-809806-6.00010-9.

[8] Vaillancourt K, Bahn O, Frenette E, Sigvaldason O. Exploring deep decarbonization pathways to 2050 for Canada using an optimization energy model framework. Appl Energy 2017;195:774-85. doi:10.1016/j.apenergy.2017.03.104.

[9] Du X-W. China's low-carbon transition for addressing climate change. Adv Clim Chang Res 2016;7:105-8. doi:10.1016/j.accre.2016.06.004.

[10] He J-K. Global low-carbon transition and China's response strategies. Adv Clim Chang Res 2016;7:204-12. doi:10.1016/j.accre.2016.06.007.

[11] International Energy Agency. World Energy Outlook 2017. International Energy Agency; 2017.

[12] International Energy Agency. Energy Technology Perspectives 2017. Catalysing Energy Technology Transformations. International Energy Agency; 2017.

[13] Koornneef J, van Breevoort P, Hamelinck C, Hendriks C, Hoogwijk M, Koop K, et al. Global potential for biomass and carbon dioxide capture, transport and storage up to 2050. Int J Greenh Gas Control 2012;11:117-32. doi:10.1016/J.IJGGC.2012.07.027.

[14] Coleman DL. Transport infrastructure rationale for carbon dioxide capture \& storage in the European Union to 2050. Energy Procedia 2009;1:1673-81. doi:10.1016/J.EGYPRO.2009.01.219.

[15] EIA. International Energy Outlook 2016. U.S. Energy Information Administration. 2016.

[16] Chen H, Ejaz Q, Gao X, Huang J, Morris J, Monier E, et al. Food, Water, Energy $\&$ Climate Outlook 2016. MIT Joint program on the science and policy of global change. 2016.

[17] BP. Energy Outlook. British Petroleum. Available at: https://www.bp.com/en/global/corporate/energy-economics/energy-outlook.html. 2018.

[18] Greenpeace. Energy [R] evolution 2015. Available at: https://www.greenpeace.org/archive-international/en/campaigns/climatechange/energyrevolution/. 2015.

[19] World Wildlife Fund. The Energy Report. 100\% Renewable energy by 2050. Available at: https://www.ecofys.com/files/files/ecofys-wwf-2011-the-energyreport.pdf. 2011. 
[20] World Energy Council. World Energy Scenarios, 2016. The grand transition. Available at: https://www.worldenergy.org/wp-content/uploads/2016/10/WorldEnergy-Scenarios-2016_Full-Report.pdf. 2016.

[21] ExxonMobil. 2017 Outlook for energy: a view to 2040. Available at: http://cdn.exxonmobil.com/ /media/global/files/outlook-for-energy/2017/2017outlook-for-energy.pdf. 2017.

[22] The Institute of Energy Economic. Asia/World Energy Outlook 2016 Consideration of 3E's+S under new energy circumstances in the wo. 2016.

[23] Kleijn R, van der Voet E, Kramer GJ, van Oers L, van der Giesen C. Metal requirements of low-carbon power generation. Energy 2011;36:5640-8. doi:10.1016/j.energy.2011.07.003.

[24] Kleijn R, van der Voet E. Resource constraints in a hydrogen economy based on renewable energy sources: An exploration. Renew Sustain Energy Rev 2010;14:2784-95. doi:10.1016/j.rser.2010.07.066.

[25] APS Physics. Energy critical elements: Securing Materials for Emerging Technologies. A report by the APS panel on public affairs \& the materials research society. 2011.

[26] Moss RLL, Tzimas E, Kara H, Willis P, Kooroshy J. Critical metals in strategic Energy Technologies. Assessing Rare Metals as Supply-Chain Bottlenecks in Low-Carbon Energy Technologies. 2012.

[27] Moss RL, Tzimas E, Willis P, Arendorf J, Espinoza LT. Critical metals in the path towards the decarbonisation of the EU energy sector. Assessing rare metals as supply-chain bottlenecks in low-carbon energy technologies. European Commission Joint Research Centre. 2013.

[28] Tokimatsu K, Wachtmeister H, McLellan B, Davidsson S, Murakami S, Höök M, et al. Energy modeling approach to the global energy-mineral nexus: A first look at metal requirements and the $2{ }^{\circ} \mathrm{C}$ target. Appl Energy 2017;207:494-509. doi:10.1016/j.apenergy.2017.05.151.

[29] Valero A, Valero A, Calvo G, Ortego A. Material bottlenecks in the future development of green technologies. Renew Sustain Energy Rev 2018;93:178200.

[30] ANFAC. European motor vehicle parc. Available at: http://www.acea.be/uploads/statistic_documents/ACEA_PARC_2014_v3.pdf. 2014.

[31] Dulac J. Global transport outlook to 2050. International Energy Agency. Available at: https://www.iea.org/media/workshops/2013/egrdmobility/DULAC_23052013.pd f. 2013.

[32] UNEP. Recycling Rates of Metals - A Status Report. A Report of the Working Group of the Global Metal Flows to the International Resource Panel. 2011.

[33] European Commission. Study on the review of the list of Critical Raw Materials. Non-critical raw materials factsheets. 2017.

[34] European Commission. Study on the review of the list of Critical Raw Materials. Critical raw materials factsheets. 2017.

[35] Alexandratos N, Bruinsma J. World agriculture towards 2030-2050. Global perspective studies team. ESA Working paper $\mathrm{n}^{\mathrm{0}} 12-03.2012$.

[36] Blanco M. NPK - wil there be enought plant nutriends to feed the world of 9 billions? Supply of and access to key nutrients NPK for fertilizers for feeding the world in 2050. 2011.

[37] FAO. World fertilizer trends and outlook to 2018. Available at: 
http://www.fao.org/3/a-i4324e.pdf. 2015.

[38] Kummamuru B. Global Bioenergy Statistics. World Bioenergy Association. 2016.

[39] IEA. Technology Roadmap. Bioenergy for Heat and Power. 2012.

[40] Calvo G, Valero A, Valero A. Assessing maximum production peak and resource availability of non-fuel mineral resources: Analyzing the influence of extractable global resources. Resour Conserv Recycl 2017;125. doi:10.1016/j.resconrec.2017.06.009.

[41] Aghbashlo M, Rosen MA. Exergoeconoenvironmental analysis as a new concept for developing thermodynamically, economically, and environmentally sound energy conversion systems. J Clean Prod 2018;187:190-204. doi:10.1016/J.JCLEPRO.2018.03.214.

[42] Aghbashlo M, Rosen MA. Consolidating exergoeconomic and exergoenvironmental analyses using the emergy concept for better understanding energy conversion systems. J Clean Prod 2018;172:696-708. doi:10.1016/J.JCLEPRO.2017.10.205.

[43] Valero A, Valero A. What are the clean reserves of fossil fuels? Resour Conserv Recycl 2012;68:126-31. doi:10.1016/j.resconrec.2012.08.004.

[44] Calvo G, Mudd G, Valero A, Valero A. Decreasing ore grades in global metallic mining: A theoretical issue or a global reality? Resources 2016;5. doi:10.3390/resources5040036.

[45] Valero A, Valero A. Thermodynamic Rarity and the Loss of Mineral Wealth. Energies 2015;8:821-36.

[46] Dominguez A, Czarnowska L, Valero A, Stanek W, Valero A. Thermoecological and exergy replacement costs of nickel processing. Energy 2014;72:103-14. doi:10.1016/j.energy.2014.05.013.

[47] Valero A, Valero A. A prediction of the exergy loss of the world's mineral reserves in the 21st century. Energy 2011;36:1848-54.

[48] Valero A, Valero A. Thanatia: the destiny of the Earth's mineral resources: A thermodynamic cradle-to-cradle assessment. World Scientific Publishing Company.; 2014.

[49] Valero A, Valero A, Gómez B. J. The crepuscular planet. A model for the exhausted continental crust. Energy 2011;36:694-707. doi:10.1016/j.energy.2010.07.017.

[50] Valero A, Dominguez A, Valero A. Exergy cost allocation of by-products in the mining and metallurgical industry. Resour Conserv Recycl 2015;102:128-42.

[51] Valero A, Valero A, Calvo G. Using thermodynamics to improve the resource efficiency indicator GDP/DMC. Resour Conserv Recycl 2015;94:110-7. doi:10.1016/j.resconrec.2014.12.001.

[52] USGS. Mineral Commodity Summaries 2016. United States Geological Service. 2016.

[53] Leontief W, Koo J, Nasar S, Sohn I. The Future of Non-Fuel Minerals in the U.S. and World Economy. Lexington, MA: Lexington Books, D.C. Heath \& Co.; 1983.

[54] Sohn I. Long-term projections of non-fuel minerals: We were wrong, but why? Resour Policy 2006;30:259-84. doi:10.1016/j.resourpol.2006.03.002.

[55] Harmsen JHM, Roes AL, Patel MK. The impact of copper scarcity on the efficiency of 2050 global renewable energy scenarios. Energy2 2013;50:62-73.

[56] Henckens MLCM, Driessen PPJ, Worrell E. Metal scarcity and sustainability, analyzing the necessity to reduce the extraction of scarce metals. Resour Conserv 
Recycl 2014;93:1-8. doi:10.1016/j.resconrec.2014.09.012.

[57] Calvo G, Valero A, Valero A, Carpintero Ó. An exergoecological analysis of the mineral economy in Spain. Energy 2015. doi:10.1016/j.energy.2015.01.083. 
Appendices

\section{Appendix A. Material intensity.}

Table A. 1. Material intensity (data in kg/MW) for each technology considered [29].

\begin{tabular}{|c|c|c|c|c|}
\hline Technology & Metal & $\begin{array}{l}\text { Material } \\
\text { intensity }\end{array}$ & Metal & $\begin{array}{l}\text { Material } \\
\text { intensity }\end{array}$ \\
\hline \multirow[t]{3}{*}{ Wind } & Aluminum & 784 & Iron & 160,214 \\
\hline & Copper & 2,060 & Neodymium & 85.29 \\
\hline & Dysprosium & 6.80 & Nickel & 111 \\
\hline \multirow[t]{8}{*}{ Solar PV } & Aluminum & 12,511 & Magnesium & 45.84 \\
\hline & Cadmium & 8.54 & Molybdenum & 9.74 \\
\hline & Copper & 3,554 & Nickel & 0.94 \\
\hline & Iron & 116,358 & Silver & 113.08 \\
\hline & Gallium & 0.35 & Silicon & $5,377.53$ \\
\hline & Germanium & 0.74 & Tin & 442 \\
\hline & Indium & 5.78 & Tellurium & 7.27 \\
\hline & Lead & 151.82 & Zinc & 4.29 \\
\hline \multirow[t]{6}{*}{ CSP } & Aluminum & 9,644 & Molybdenum & 142.40 \\
\hline & Chromium & 2,800 & Nickel & 1,284 \\
\hline & Copper & 2,480 & Silver & 14.20 \\
\hline & Iron & 851,200 & Titanium & 15 \\
\hline & Magnesium & 2,840 & Vanadium & 2 \\
\hline & Manganese & 3,480 & Zinc & 950 \\
\hline \multirow[t]{8}{*}{ Solar thermal } & Aluminum & 228.38 & Molybdenum & 162.46 \\
\hline & Arsenic & 0.01 & Nickel & 162.50 \\
\hline & Chromium & $3,249.33$ & Phosphorous & 14.62 \\
\hline & Copper & $2,988.57$ & Potassium & 37.30 \\
\hline & Iron & $28,390.02$ & Silicon & $1,615.29$ \\
\hline & Lead & 0.36 & Tin & 0.04 \\
\hline & Magnesium & 149.86 & Titanium & 21.20 \\
\hline & Manganese & 324.94 & Zinc & 4.72 \\
\hline \multirow[t]{4}{*}{ Geothermal } & Aluminum & 6,790 & Nickel & 240 \\
\hline & Chromium & 200 & Tin & 3.60 \\
\hline & Copper & 2,440 & Zinc & 110 \\
\hline & Iron & 14,900 & & \\
\hline \multirow[t]{2}{*}{ Gas power } & Aluminum & 750 & Iron & 5,500 \\
\hline & Copper & 750 & & \\
\hline \multirow[t]{3}{*}{ Nuclear } & Aluminum & 200 & Iron & 58,904 \\
\hline & Chromium & 2,190 & Manganese & 75.19 \\
\hline & Copper & 1,470 & & \\
\hline \multirow[t]{2}{*}{ Hydropower } & Chromium & 96,000 & Manganese & 5,760 \\
\hline & Iron & $1,242,000$ & & \\
\hline
\end{tabular}


Table A. 2. Material intensity for vehicles (data in grams per unit) [29].

\begin{tabular}{|c|c|c|c|}
\hline & ICEV & PHEV & BEV \\
\hline Ag & 17.50 & 28 & 29.80 \\
\hline Al & 110,544 & 115,544 & 200,000 \\
\hline $\mathrm{Ce}$ & 46.96 & 49.68 & 0.16 \\
\hline Co & - & $2,659.22$ & $10,636.88$ \\
\hline $\mathrm{Cr}$ & $12,789.17$ & $12,789.17$ & 11,850 \\
\hline $\mathrm{Cu}$ & 28,500 & $59,166.66$ & 150,000 \\
\hline Dy & 14.71 & 165.72 & 224.63 \\
\hline $\mathbf{F e}$ & $806,144.17$ & $806,144.17$ & 746,945 \\
\hline $\mathbf{G a}$ & 0.42 & 0.81 & 1.13 \\
\hline Gd & 0.18 & 0.18 & 0.18 \\
\hline Ge & - & 0.05 & 0.08 \\
\hline In & 0.38 & 0.38 & 0.38 \\
\hline La & 4.04 & 7.38 & 7.38 \\
\hline $\mathbf{L i}$ & 1.36 & $2,126.09$ & $8,504.37$ \\
\hline Mn & $5,968.28$ & $5,968.28$ & 5,530 \\
\hline Mo & $3,410.45$ & $3,410.45$ & $3,410.45$ \\
\hline $\mathbf{N b}$ & 426.31 & 426.31 & 426.31 \\
\hline Nd & 162.30 & 552.79 & 749.30 \\
\hline $\mathbf{N i}$ & $4,263.05$ & $17,863.81$ & $58,025.59$ \\
\hline $\mathbf{P b}$ & 9,750 & 9,750 & - \\
\hline Pd & 1.24 & 0.95 & - \\
\hline Pr & 16.54 & 51.49 & 98.01 \\
\hline $\mathbf{P t}$ & 2.25 & 5.51 & - \\
\hline Ta & 6.99 & 10.83 & 10.83 \\
\hline $\mathbf{V}$ & 852.61 & 852.61 & 790 \\
\hline
\end{tabular}

Table A.3. Nuclear and gas power material intensity for steel (data in kg/MW) [29].

791

\begin{tabular}{lcc}
\hline & Gas power & Nuclear \\
\hline $\mathbf{A l}$ & 750 & 200 \\
\hline $\mathbf{C u}$ & - & 2,190 \\
\hline $\mathbf{C r}$ & 750 & 1,470 \\
\hline $\mathbf{F e}$ & 5,500 & 58,904 \\
\hline $\mathbf{M n}$ & - & 75 \\
\hline
\end{tabular}




\section{Appendix B. Exergy analysis.}

Table B.1. Exergy replacement costs (ERC) values for the elements considered (data in GJ/ton) $[48,57]$.

\begin{tabular}{lclclc}
\hline Element & ERC (GJ/ton) & Element & ERC (GJ/ton) & Element & ERC (GJ/ton) \\
\hline $\mathbf{A g}$ & 7,371 & $\mathbf{G e}$ & 23,749 & $\mathbf{P b}$ & 37 \\
\hline $\mathbf{A l}$ & 627 & $\mathbf{I n}$ & 360,598 & $\mathbf{P d}$ & $8,983,377$ \\
\hline $\mathbf{A s}$ & 400 & $\mathbf{K}$ & 665 & $\mathbf{P r}$ & 577 \\
\hline $\mathbf{C d}$ & 5,898 & $\mathbf{L a}$ & 39 & $\mathbf{P t}$ & $4,491,688$ \\
\hline $\mathbf{C e}$ & 97 & $\mathbf{L i}$ & 546 & $\mathbf{S i}$ & 0.73 \\
\hline $\mathbf{C o}$ & 10,872 & $\mathbf{M g}$ & 136 & $\mathbf{S n}$ & 426 \\
\hline $\mathbf{C r}$ & 5 & $\mathbf{M n}$ & 16 & $\mathbf{T a}$ & 482,828 \\
\hline $\mathbf{C u}$ & 292 & $\mathbf{M o}$ & 908 & $\mathbf{T e}$ & 2,236 \\
\hline $\mathbf{D y}$ & 348 & $\mathbf{N b}$ & 4,422 & $\mathbf{T i}$ & 4.94 \\
\hline Fe & 18 & $\mathbf{N d}$ & 78 & $\mathbf{V}$ & 1,055 \\
\hline $\mathbf{G a}$ & 144,828 & $\mathbf{N i}$ & 524 & $\mathbf{Z n}$ & 1,627 \\
\hline $\mathbf{G d}$ & 478 & $\mathbf{P}$ & 0.35 & & \\
\hline
\end{tabular}

Data presented in the International Energy Agency reports are in PJ, so to represent all the material flows in one single diagram, we have transformed all the information into Mtoe using a conversion factor $(1 \mathrm{Mtoe}=42,000,000 \mathrm{GJ})$. 